\title{
Appendice 1
}

MEDLINE (Ovid) and HMIC search strategy

1. cancer.mp. or Neoplasms/

2. cancer ${ }^{\star} . \mathrm{mp}$. [mp=title, abstract, original title, name of substance word, subject heading word, keyword heading word, protocol supplementary concept word, rare disease supplementary concept word, unique identifier, synonyms]

3. neoplas ${ }^{*} . \mathrm{mp}$. [mp=title, abstract, original title, name of substance word, subject heading word, keyword heading word, protocol supplementary concept word, rare disease supplementary concept word, unique identifier, synonyms]

4. malignan*.mp. [mp=title, abstract, original title, name of substance word, subject heading word, keyword heading word, protocol supplementary concept word, rare disease supplementary concept word, unique identifier, synonyms]

5. carcinoma*.mp. [mp=title, abstract, original title, name of substance word, subject heading word, keyword heading word, protocol supplementary concept word, rare disease supplementary concept word, unique identifier, synonyms]

6. sarcoma ${ }^{*} \cdot m p$. [mp=title, abstract, original title, name of substance word, subject heading word, keyword heading word, protocol supplementary concept word, rare disease supplementary concept word, unique identifier, synonyms]

7. oncolog ${ }^{*} . \mathrm{mp}$. [mp=title, abstract, original title, name of substance word, subject heading word, keyword heading word, protocol supplementary concept word, rare disease supplementary concept word, unique identifier, synonyms]

8. tumo? ${ }^{*} . m p . ~[m p=t i t l e, ~ a b s t r a c t$, original title, name of substance word, subject heading word, keyword heading word, protocol supplementary concept word, rare disease supplementary concept word, unique identifier, synonyms]

9. adenocarcinoma ${ }^{\star} \cdot \mathrm{mp} .[\mathrm{mp}=$ title, abstract, original title, name of substance 
word, subject heading word, keyword heading word, protocol supplementary concept word, rare disease supplementary concept word, unique identifier, synonyms]

10. infiltrat ${ }^{\star} . m p$. [mp=title, abstract, original title, name of substance word, subject heading word, keyword heading word, protocol supplementary concept word, rare disease supplementary concept word, unique identifier, synonyms]

11. medullary.mp. [ $\mathrm{mp}=$ title, abstract, original title, name of substance word, subject heading word, keyword heading word, protocol supplementary concept word, rare disease supplementary concept word, unique identifier, synonyms]

12. intraductal.mp. [mp=title, abstract, original title, name of substance word, subject heading word, keyword heading word, protocol supplementary concept word, rare disease supplementary concept word, unique identifier, synonyms]

\section{1 or 2 or 3 or 4 or 5 or 6 or 7 or 8 or 9 or 10 or 11 or 12}

14. follow-up.mp. [mp=title, abstract, original title, name of substance word, subject heading word, keyword heading word, protocol supplementary concept word, rare disease supplementary concept word, unique identifier, synonyms]

15. followup ${ }^{*}$.mp. [mp=title, abstract, original title, name of substance word, subject heading word, keyword heading word, protocol supplementary concept word, rare disease supplementary concept word, unique identifier, synonyms]

16. follow-up care.mp. [mp=title, abstract, original title, name of substance word, subject heading word, keyword heading word, protocol supplementary concept word, rare disease supplementary concept word, unique identifier, synonyms]

17. follow-up stud ${ }^{*}$.mp. [mp=title, abstract, original title, name of substance word, subject heading word, keyword heading word, protocol supplementary concept word, rare disease supplementary concept word, unique identifier, synonyms]

18. postsurgery.mp. [mp=title, abstract, original title, name of substance word, 
subject heading word, keyword heading word, protocol supplementary concept word, rare disease supplementary concept word, unique identifier, synonyms]

19. post surgery.mp. [mp=title, abstract, original title, name of substance word, subject heading word, keyword heading word, protocol supplementary concept word, rare disease supplementary concept word, unique identifier, synonyms]

20. postsurgical ${ }^{*} . \mathrm{mp}$. [mp=title, abstract, original title, name of substance word, subject heading word, keyword heading word, protocol supplementary concept word, rare disease supplementary concept word, unique identifier, synonyms]

21. post surgical ${ }^{*} . \mathrm{mp}$. [ $\mathrm{mp}=$ title, abstract, original title, name of substance word, subject heading word, keyword heading word, protocol supplementary concept word, rare disease supplementary concept word, unique identifier, synonyms]

22. postoperat ${ }^{*}$.mp. [mp=title, abstract, original title, name of substance word, subject heading word, keyword heading word, protocol supplementary concept word, rare disease supplementary concept word, unique identifier, synonyms]

23. post-operat ${ }^{\star} . \mathrm{mp}$. [ $\mathrm{mp}=$ title, abstract, original title, name of substance word, subject heading word, keyword heading word, protocol supplementary concept word, rare disease supplementary concept word, unique identifier, synonyms]

24. continuity of patient care.mp. [mp=title, abstract, original title, name of substance word, subject heading word, keyword heading word, protocol supplementary concept word, rare disease supplementary concept word, unique identifier, synonyms]

25. disease management.mp. [mp=title, abstract, original title, name of substance word, subject heading word, keyword heading word, protocol supplementary concept word, rare disease supplementary concept word, unique identifier, synonyms]

26. surveillance.mp. [mp=title, abstract, original title, name of substance word, subject heading word, keyword heading word, protocol supplementary concept word, rare disease supplementary concept word, unique identifier, 
synonyms]

27. routine test ${ }^{\star} . \mathrm{mp}$. [mp=title, abstract, original title, name of substance word, subject heading word, keyword heading word, protocol supplementary concept word, rare disease supplementary concept word, unique identifier, synonyms]

28. disease progression.mp. [mp=title, abstract, original title, name of substance word, subject heading word, keyword heading word, protocol supplementary concept word, rare disease supplementary concept word, unique identifier, synonyms]

29. 14 or 15 or 16 or 17 or 18 or 19 or 20 or 21 or 22 or 23 or 24 or 25 or 26 or 27 or 28

30. Patient Care Team/ or Primary Health Care/ or Family Practice/

31. shared care.mp. [mp=title, abstract, original title, name of substance word, subject heading word, keyword heading word, protocol supplementary concept word, rare disease supplementary concept word, unique identifier, synonyms]

32. sharing of care.mp. [mp=title, abstract, original title, name of substance word, subject heading word, keyword heading word, protocol supplementary concept word, rare disease supplementary concept word, unique identifier, synonyms]

33. co-management.mp. [ $\mathrm{mp}=$ title, abstract, original title, name of substance word, subject heading word, keyword heading word, protocol supplementary concept word, rare disease supplementary concept word, unique identifier, synonyms]

34. collaborative care.mp. [mp=title, abstract, original title, name of substance word, subject heading word, keyword heading word, protocol supplementary concept word, rare disease supplementary concept word, unique identifier, synonyms]

35. care coordination. $\mathrm{mp}$. [mp=title, abstract, original title, name of substance word, subject heading word, keyword heading word, protocol supplementary concept word, rare disease supplementary concept word, unique identifier, synonyms] 
36. coordinated care.mp. [mp=title, abstract, original title, name of substance word, subject heading word, keyword heading word, protocol supplementary concept word, rare disease supplementary concept word, unique identifier, synonyms]

37. (referral and consultation).mp. [mp=title, abstract, original title, name of substance word, subject heading word, keyword heading word, protocol supplementary concept word, rare disease supplementary concept word, unique identifier, synonyms]

38. cooperative behavio?r.mp. [mp=title, abstract, original title, name of substance word, subject heading word, keyword heading word, protocol supplementary concept word, rare disease supplementary concept word, unique identifier, synonyms]

39. delivery of health care.mp. [mp=title, abstract, original title, name of substance word, subject heading word, keyword heading word, protocol supplementary concept word, rare disease supplementary concept word, unique identifier, synonyms]

40.30 or 31 or 32 or 33 or 34 or 35 or 36 or 37 or 38 or 39

41. shared service ${ }^{*} . \mathrm{mp}$. [mp=title, abstract, original title, name of substance word, subject heading word, keyword heading word, protocol supplementary concept word, rare disease supplementary concept word, unique identifier, synonyms]

42. 40 or 41

43. 13 and 29 and 42

44. limit 43 to (humans)

MEDLINE results: 474

HMIC results:77

British Nursing Index search strategy

(ab(follow up) OR ab(follow-up) OR ab(followup*) OR ab(postsurgery) OR $a b$ (post-surgery) OR ab(postsurgical ${ }^{\star}$ ) OR ab(post surgical ${ }^{\star}$ ) OR 
$a b\left(\right.$ postoperat $\left.^{\star}\right)$ OR $a b\left(\right.$ post-operat $\left.{ }^{\star}\right)$ OR $a b$ (continuity of patient care) OR $a b$ (disease management) $O R$ ab(surveillance) $O R$ ab(routine test*) OR $a b$ (disease progression) $O R$ ab(aftercare) $O R$ ab(survivorship)) AND (ab(shared care) OR ab(sharing of care) OR $a b$ (co-management) OR $\mathrm{ab}$ (collaborative care) $\mathrm{OR}$ ab(care coordination) OR $\mathrm{ab}$ (coordinated care) OR $a b$ (referral AND consultation) OR $a b$ (cooperative behavio* $r$ ) OR ab(delivery of health care) OR ab(shared service*)) AND ((SU.EXACT("Cancer : Pain") OR SU.EXACT("Lung Cancer") OR SU.EXACT("Colorectal Cancer") OR SU.EXACT("Cervical Cancer") OR SU.EXACT("Cancer : Services") OR SU.EXACT("Cancer : Children") OR SU.EXACT("Cancer : Nursing") OR SU.EXACT("Cancer : Radiotherapy") OR SU.EXACT("Skin Cancer") OR SU.EXACT("Cancer : Chemotherapy") OR SU.EXACT("Testicular Cancer") OR SU.EXACT("Head and Neck Cancer") OR SU.EXACT("Cancer : Surgery") OR SU.EXACT("Cancer : Counselling") OR SU.EXACT("Cancer") OR SU.EXACT("Ovarian Cancer") OR SU.EXACT("Breast Cancer") OR SU.EXACT("Prostate Cancer") OR SU.EXACT("Cancer : Alternative Therapies")) OR cancer* OR neoplas* OR malignan* OR carcinoma* OR sarcoma* OR oncolog* OR tumo* $r^{\star}$ OR adenocarcinoma* OR infiltrat* OR medullary OR intraductal)

Results: 320

CINAHL (EBSCO) search strategy

S48 S13 AND S33 AND S47

S47 S35 OR S36 OR S37 OR S38 OR S39 OR S40 OR S41 OR S42 OR S43 OR S44 OR S45 OR S46

S46 "inter-organizational coordination"

S45 "shared model"

S44 "integrated care"

S43 "delivery of health care"

S42 "shared service ${ }^{* "}$ 
S40 "referral and consultation"

S39 "coordinated care"

S38 "care coordination"

S37 "collaborative care"

844

S36 "sharing of care" 66

S35 co-management 94

S34 (MM "Shared Services, Health Care") OR "shared care" 686

S33 S14 OR S15 OR S16 OR S17 OR S18 OR S19 OR S20 OR S21 OR S22 OR S23 OR S24 OR S25 OR S26 OR S27 OR S28 OR S29 OR S30 OR S31 OR S32

S32 post treatment

S31 post-treatment

S30 rehabilitation

113,235

S29 posttreatment

S28 survivorship

2,606

S27 aftercare 607

S26 "disease progression"

S25 surveillance

29,431

S24 "disease management"

10,805

S23 "continuity of patient care"

S22 post-operat ${ }^{*}$

S21 postoperat*

66,470

S20 post surgical ${ }^{*}$ 
S19 postsurgical*

S18 post surgery

S17 postsurgery

S16 followup*

S15 follow up

98,975

S14 (MM "After Care") OR "follow-up"

100,285

S13 S1 OR S2 OR S3 OR S4 OR S5 OR S6 OR S7 OR S8 OR S9 OR S10 OR S11 OR S12 286,237

S12 intraductal

S11 medullary

S10 infiltrat*

S9 adenocarcinoma*

S8 tumo? $r^{\star}$

S7 oncolog*

S6 sarcoma

S5 carcinoma*

S4 malignan*

S3 neoplas*

S2 cancer* $^{*}$

178,269

S1 (MM "Cancer Patients") OR (MM "Cancer Survivors") OR "cancer"

Results: 437 
Cochrane library search strategy

\#1 MeSH descriptor: [Neoplasms] explode all trees

\#2 cancer*:ti,ab,kw (Word variations have been searched)

\#3 neoplas*:ti,ab,kw (Word variations have been searched)

\#4 malignan*:ti,ab,kw (Word variations have been searched)

\#5 carcinoma*:ti,ab,kw (Word variations have been searched)

\#6 sarcoma*:ti,ab,kw (Word variations have been searched)

\#7 oncolog*:ti,ab,kw (Word variations have been searched)

\#8 tumo? $r^{\star}: t i, a b, k w \quad$ (Word variations have been searched)

\#9 adenocarcinoma*:ti,ab,kw (Word variations have been searched)

\#10infiltrat* ${ }^{\star} \mathrm{ti}, \mathrm{ab}, \mathrm{kw} \quad$ (Word variations have been searched)

\#11 medullary:ti,ab,kw (Word variations have been searched)

\#12intraductal:ti,ab,kw (Word variations have been searched)

$\# 13 \# 1$ or \#2 or \#3 or \#4 or \#5 or \#6 or \#7 or \#8 or \#9 or \#10 or \#11 or \#12

\#14MeSH descriptor: [Aftercare] explode all trees

\#15"follow up*" (Word variations have been searched)

\#16follow-up*:ti,ab,kw (Word variations have been searched)

\#17followup*:ti,ab,kw (Word variations have been searched)

\#18postsurgery:ti,ab,kw (Word variations have been searched)

\#19post surgery (Word variations have been searched)

\#20 postsurgical ${ }^{\star}: \mathrm{ti}, \mathrm{ab}, \mathrm{kw} \quad$ (Word variations have been searched)

\#21 post surgical*:ti,ab,kw (Word variations have been searched) 
\#22post-surgery:ti,ab,kw (Word variations have been searched) \#23post-surgical ${ }^{*}: \mathrm{ti}, \mathrm{ab}, \mathrm{kw} \quad$ (Word variations have been searched) \#24postoperat*:ti,ab,kw (Word variations have been searched) \#25 post-operat*:ti,ab,kw (Word variations have been searched) \#26post operat*:ti,ab,kw (Word variations have been searched) \#27"continuity of patient care" (Word variations have been searched) \#28"disease management" (Word variations have been searched) \#29surveillance:ti,ab,kw (Word variations have been searched) \#30"disease progression" (Word variations have been searched) \#31 aftercare (Word variations have been searched) \#32survivorship (Word variations have been searched) \#33"post treatment" (Word variations have been searched) \#34posttreatment (Word variations have been searched) \#35rehabilitation (Word variations have been searched) $\# 36 \# 14$ or \#15 or \#16 or \#17 or \#18 or \#19 or \#20 or \#21 or \#22 or \#23 or \#24 or \#25 or \#26 or \#27 or \#28 or \#29 or \#30 or \#31 or \#32 or \#33 or \#34 or \#35 \#37 MeSH descriptor: [Referral and Consultation] explode all trees \#38shared care:ti,ab,kw (Word variations have been searched) \#39sharing of care:ti,ab,kw (Word variations have been searched) \#40shared service*:ti,ab,kw (Word variations have been searched) \#41 collaborative care:ti,ab,kw (Word variations have been searched) \#42co-management (Word variations have been searched) \#43care coordination:ti,ab,kw (Word variations have been searched) 
\#44coordinated care:ti,ab,kw (Word variations have been searched)

\#45referral and consultation:ti,ab,kw (Word variations have been searched) \#46cooperative behavio?r:ti,ab,kw (Word variations have been searched) \#47"delivery of health care" (Word variations have been searched) \#48"integrated care" (Word variations have been searched) \#49"shared model" (Word variations have been searched) \#50 inter-organizational coordination (Word variations have been searched) $\# 51 \# 37$ or \#38 or \#39 or \#40 or \#41 or \#42 or \#43 or \#44 or \#45 or \#46 or \#47 or \#48 or \#49 or \#50 in Trials and Economic Evaluations (Word variations have been searched)

\#52\#13 and \#36 and \#51

Results: 370

Social care online search strategy

shared care-5/7/2017:

cancer

- AllFields:'cancer*'

- OR AllFields:'neoplas*'

- OR AllFields:'malignan*'

- OR AllFields:'carcinoma*'

- OR AllFields:'sarcoma*'

- OR AllFields:'oncolog*'

- OR AllFields:'tumor*' 
- OR AllFields:'adenocarcinoma*'

- OR AllFields:'infiltrat*'

- OR AllFields:'medullary'

- OR AllFields:'intraductal'

AND

follow up-5/7/2017

- AllFields:'aftercare'

- OR AllFields:"'follow up*"'

- OR AllFields:'follow-up*'

- OR AllFields:'followup*'

- OR AllFields:'postsurgery'

- OR AllFields:'post surgery'

- OR AllFields:'postsurgical ${ }^{\star \prime}$

- OR AllFields:'post surgical'

- OR AllFields:'post-surgery'

- OR AllFields:'post-surgical'

- OR AllFields:'postoperat ${ }^{\star \prime}$

- OR AllFields:'post-operat*'

- OR AllFields:'post operat"

- OR AllFields:'"continuity of patient care"'

- OR AllFields:'"disease management"' 
- OR AllFields:'surveillance'

- OR AllFields:'"disease progression"'

- OR AllFields:'survivorship'

- OR AllFields:"post treatment"'

- OR AllFields:'posttreatment'

- OR AllFields:'post treatment'

- OR AllFields:'rehabilitation'

AND

shared care-5/7/2017

- AllFields:'shared care'

- OR AllFields:'sharing of care'

- OR AllFields:'shared service*'

- OR AllFields:'collaborative care'

- OR AllFields:'co-management'

- OR AllFields:'care coordination'

- OR AllFields:'coordinated care'

- OR AllFields:'referral and consultation'

- OR AllFields:'cooperative behavio r'

- OR AllFields:'"delivery of health care"'

- OR AllFields:"'integrated care"'

- OR AllFields:"'shared model"' 
- OR AllFields:'inter-organizational coordination'

- OR AllFields:'referral and consultation'

- OR AllFields:'coordination of care'

- OR AllFields:'team-working'

- OR AllFields:'partnership*'

Results: 210 


\section{Appendice 2 Critical Appraisal Skills Programme (CASP) Randomised \\ Controlled Trials Checklist}

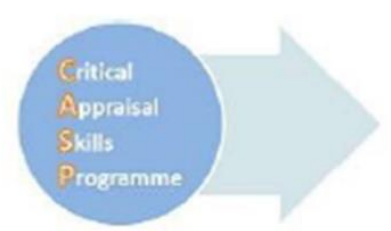

\section{1 questions to help you make sense of a trial}

How to use this appraisal tool

Three broad issues need to be considered when appraising the report of a randomised controlled trial:

- Are the results of the trial valid?

- What are the results?

- Will the results help locally? (Section C)

The 11 questions on the following pages are designed to help you think about these issues systematically.

The first two questions are screening questions and can be answered quickly. If the answer to both is yes, it is worth proceeding with the remaining questions.

There is some degree of overlap between the questions, you are asked to record a yes, no or can't tell to most of the questions. A number of prompts are given after each question. These are designed to remind you why the question is important. Record your reasons for your answers in the spaces provided.

There will not be time in the small groups to answer them all in detail!

These checklists were designed to be used as educational tools as part of a workshop

(9)ASP This work is licensed under the Creative Commons Attribution - Noncommercial-ShareAlike 3.0 Unported License. To view a copy of this license, visit hrto //creativecommons.org/licenses/bv-ncosa/3.0/ www.casp-uk.net

(3) Critical Appraisal Skills Programme (CASP) Randomised Controlled Trials Checklist 31.05.13 1 1 
(A) Are the results of the trial valid?

$\underline{\text { Screening Questions }}$

1. Did the trial address a clearly focused issue? $\quad \square$ Yes $\square$ Can't tell $\square$ No Consider: An issue can be focused in terms of

- The population studied

- The intervention given

- The comparator given

- The outcomes considered

2. Was the assignment of patients to treatments $\quad \square$ Yes $\square$ Can't tell $\square$ No randomised?

Consider:

- How was this carried out, some mechods

may produce broken allocation concealment

- Was the allocation concealed from researchers?

Is it worth continuing?

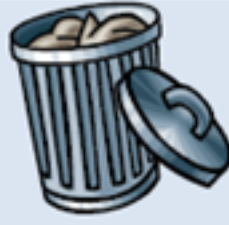

(3) Critical Appraisal Skills Programme (CASP) Randomised Controlled Trials Checklist 31.05.13 


\section{Detailed questions}

3. Were patients, health workers and study

$\square_{\text {Yes }} \square_{\text {Can't tell }} \square_{\text {No }}$ personnel blinded?

consider:

- Health workers could be; clinicians, nurses etc

- Study personnel - especially outcome assessors

4. Were the groups similar at the start of the trial?

$\square_{\text {yes }} \square_{\text {can't tell }} \square_{\text {No }}$

Consider: Look at

- Cther factors that might affect the outcome such as age,

sex, social class, these may be called baseline characteristics

5. Aside from the experimental intervention, $\quad \square$ Yes $\square$ Can't tell $\square$ No were the groups treated equally?

(3) Critical Appraisal Skills Programme (CASP) Randomised Controlled Trials Checklist 31.05.13 3 


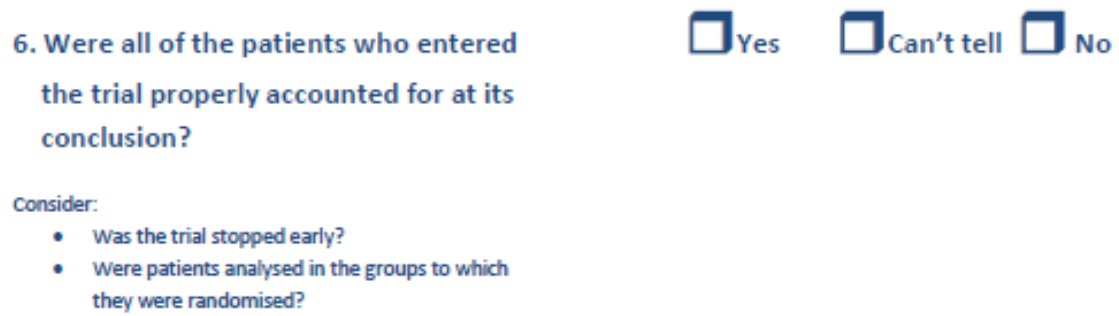

- Were patients analysed in the groups to which they were randomised?

\section{(B) What are the results?}

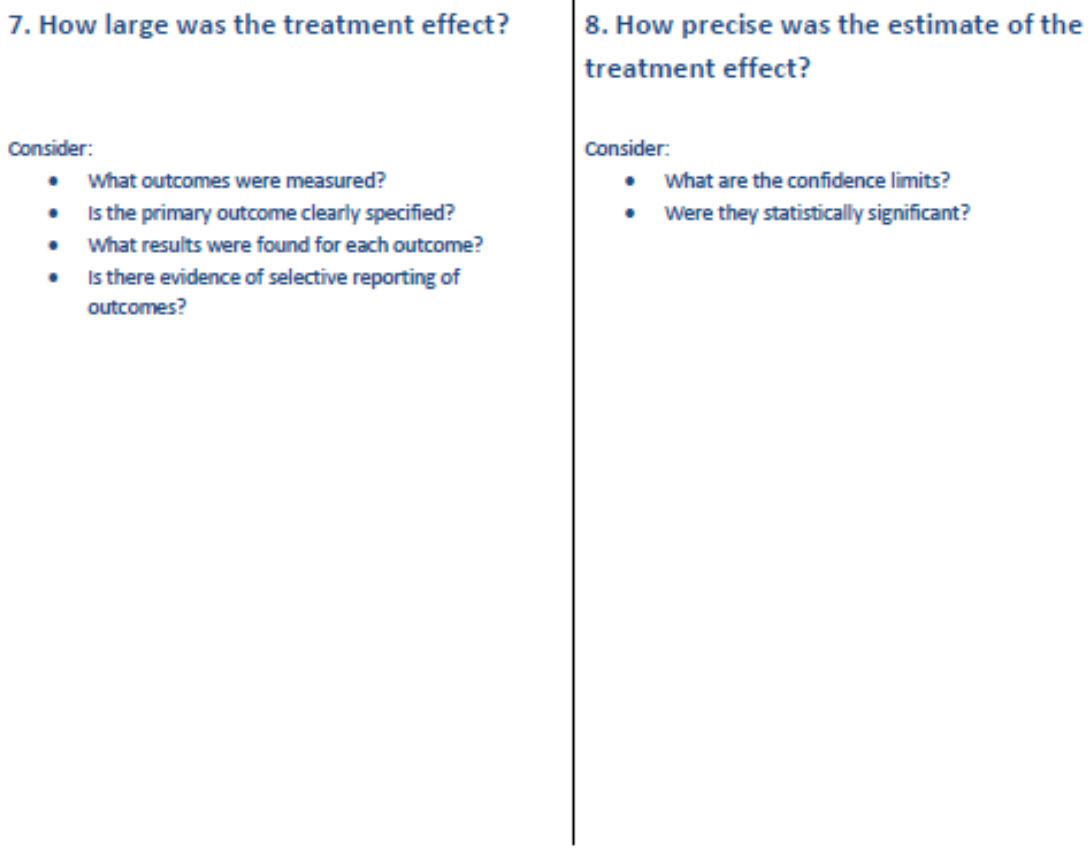

(6) Critical Appraisal Skills Programme (CASP) Randomised Controlled Trials Checklist 31.05.13 4 


\section{(C) Will the results help locally?}

9. Can the results be applied in your context? $\quad \square$ Yes $\square$ Can't tell $\square$ No (or to the local population?)

consider:

- Do you have reason to believe that your population

of interest is different to that in the trial

- If so, in what way?

10. Were all clinically important outcomes

$\square_{\text {Yes }} \square_{\text {Can't tell }} \square_{\text {No }}$ considered?

Consider:

- Is there other information you would like to have seen?

- Was the need for this trial clearly described?

11. Are the benefits worth the harms and costs?

$\square_{\text {Yes }} \square$ can't tell $\square_{\text {No }}$

Consider:

- Even if this is not addressed by the trial, what do you think? 
Appendice 3 Health Care Practice R\&D Unit (HCPRDU) quantitative research checklists 


\section{Evaluation Tool for Quantitative Research Studies}

Building on work within a project exploring the feasibility of undertaking systematic reviews of research literature on effectiveness and outcomes in social care, a set of evaluation tools have been developed to assist in the critical appraisal of research studies. The evaluation tool for quantitative studies contains six sub-sections: study evaluative overview; study, setting and sample; ethics; group comparability and outcome measurement; policy and practice implications; and other comments. It provides a template of key questions to assist in the critical appraisal of quantitative research studies.

\begin{tabular}{|c|c|}
\hline Review Area & Key Questions \\
\hline \multicolumn{2}{|c|}{ (1) STUDY OVERVIEW } \\
\hline $\begin{array}{l}\text { Bibliographic } \\
\text { Details }\end{array}$ & 0. Author, title, source (publisher and place of publication), year \\
\hline Purpose & $\begin{array}{l}\text { 1. What are the aims of the study? } \\
\text { 2. If the paper is part of a wider study, what are its aims? }\end{array}$ \\
\hline Key Findings & 3. What are the key findings of the study? \\
\hline $\begin{array}{l}\text { Evaluative } \\
\text { Summary }\end{array}$ & $\begin{array}{l}\text { 4. What are the strengths and weaknesses of the study and theory, policy } \\
\text { and practice implications? }\end{array}$ \\
\hline \multicolumn{2}{|c|}{ (2) STUDY, SETTING, SAMPLE AND ETHICS } \\
\hline The Study & $\begin{array}{l}\text { 5. What type of study is this? } \\
\text { 6. What was the intervention? } \\
\text { 7. What was the comparison intervention? } \\
\text { 8. Is there sufficient detail given of the nature of the intervention and the } \\
\text { comparison intervention? } \\
\text { 9. What is the relationship of the study to the area of the topic review? }\end{array}$ \\
\hline Setting & 10. Within what geographical and care setting was the study carried out? \\
\hline Sample & $\begin{array}{l}\text { 11. What was the source population? } \\
\text { 12. What were the inclusion criteria? } \\
\text { 13. What were the exclusion criteria? } \\
\text { 14. How was the sample selected? } \\
\text { 15. If more than one group of subjects, how many groups were there, and } \\
\text { how many people were in each group? } \\
\text { 16. How were subjects allocated to the groups? } \\
\text { 17. What was the size of the study sample, and of any separate groups? } \\
\text { 18. Is the achieved sample size sufficient for the study aims and to } \\
\text { warrant the conclusions drawn? } \\
\text { 19. Is information provided on loss to follow up? } \\
\text { 20. Is the sample appropriate to the aims of the study? } \\
\text { 21. What are the key sample characteristics, in relation to the topic area } \\
\text { being reviewed? }\end{array}$ \\
\hline \multicolumn{2}{|l|}{ (3) ETHICS } \\
\hline Ethics & $\begin{array}{l}\text { 22. Was Ethical Committee approval obtained? } \\
\text { 23. Was informed consent obtained from participants of the study? } \\
\text { 24. Have ethical issues been adequately addressed? }\end{array}$ \\
\hline
\end{tabular}




\begin{tabular}{|c|c|}
\hline \multicolumn{2}{|c|}{ (4) GROUP COMPARABILITY AND OUTCOME MEASUREMENT } \\
\hline $\begin{array}{l}\text { Comparable } \\
\text { Groups }\end{array}$ & $\begin{array}{l}\text { 25. If there was more than one group was analysed, were the groups } \\
\text { comparable before the intervention? In what respects were they } \\
\text { comparable and in what were they not? } \\
26 \text {. How were important confounding variables controlled (e.g. matching, } \\
\text { randomisation, in the analysis stage)? } \\
27 \text {. Was this control adequate to justify the author's conclusions? } \\
\text { 28. Were there other important confounding variables controlled for in } \\
\text { the study design or analyses and what were they? } \\
\text { 29. Did the authors take these into account in their interpretation of the } \\
\text { findings? }\end{array}$ \\
\hline $\begin{array}{l}\text { Outcome } \\
\text { Measurement }\end{array}$ & $\begin{array}{l}\text { 30. What were the outcome criteria? } \\
\text { 31. What outcome measures were used? } \\
\text { 32. Are the measures appropriate, given the outcome criteria? } \\
\text { 33. What other (e.g. process, cost) measures are used? } \\
\text { 34. Are the measures well validated? } \\
\text { 35. Are the measures of known responsive to change? } \\
\text { 36. Whose perspective do the outcome measures address (professional, } \\
\text { service, user, carer)? } \\
\text { 37. Is there a sufficient breath of perspective? } \\
\text { 38. Are the outcome criteria useful/appropriate within routine practice? } \\
\text { 39. Are the outcome measures useful/appropriate within routine } \\
\text { practice? }\end{array}$ \\
\hline $\begin{array}{l}\text { Time Scale of } \\
\text { Measurement }\end{array}$ & $\begin{array}{l}\text { 40. What was the length of follow-up, and at what time points was } \\
\text { outcome measurement made? } \\
\text { 41. Is this period of follow-up sufficient to see the desired effects? }\end{array}$ \\
\hline \multicolumn{2}{|c|}{ (5) POLICY AND PRACTICE IMPLICATIONS } \\
\hline Implications & $\begin{array}{l}\text { 42. To what setting are the study findings generalisable? (For example, } \\
\text { is the setting typical or representative of care settings and in what } \\
\text { respects?) } \\
\text { 43. To what population are the study's findings generalisable? } \\
\text { 44. Is the conclusion justified given the conduct of the study (For } \\
\text { example, sampling procedure; measures of outcome used and results } \\
\text { achieved?) } \\
\text { 45. What are the implications for policy? } \\
\text { 46. What are the implications for service practice? }\end{array}$ \\
\hline \multicolumn{2}{|c|}{ (6) OTHER COMMENTS } \\
\hline Other Comments & $\begin{array}{l}\text { 47. What were the total number of references used in the study? } \\
\text { 48. Are there any other noteworthy features of the study? } \\
\text { 49. List other study references }\end{array}$ \\
\hline Reviewer & $\begin{array}{l}\text { 50. Name of reviewer } \\
\text { 51. Review date }\end{array}$ \\
\hline
\end{tabular}

Source: Long AF, Godfrey M, Randall T, Brettle AJ and Grant MJ (2002) Developing Evidence Based Social Care Policy and Practice. Part 3: Feasibility of Undertaking Systematic Reviews in Social Care. Leeds: Nuffield Institute for Health.

Note: This tool was developed while the lead author was at the Health Care Practice R\&D Unit (HCPRDU) at the University of Salford. It has since been slightly modified. 


\section{Appendice 4 Health Care Practice R\&D Unit (HCPRDU) mixed methods research checklists}

Evaluative Tool for Mixed Method Studies

\section{Evaluation Tool for 'Mixed Methods' Study Designs}

The 'mixed method' evaluation tool was developed from the evaluation tools for 'quantitative' and 'qualitative' studies,' themselves created within the context of a project exploring the feasibility of undertaking systematic reviews of research literature on effectiveness and outcomes in social care. The 'mixed method' tool draws on appropriate questions from the quantitative and qualitative evaluation tools. It provides a template of key questions to assist in the critical appraisal of studies using more than one method."

\begin{tabular}{|c|c|}
\hline Review Area & Key Questions \\
\hline \multicolumn{2}{|c|}{ (1) STUDY EVALUATIVE OVERVIEW } \\
\hline Bibliographic Details & - Author, title, source (publisher and place of publication), year \\
\hline Purpose & $\begin{array}{l}\text { - What are the aims of this paper? } \\
\text { - If the paper is part of a wider study, what are its aims? }\end{array}$ \\
\hline Key Findings & - What are the key findings? \\
\hline Evaluative Summary & $\begin{array}{l}\text { - What are the strengths and weaknesses of the study and theory, } \\
\text { policy and practice implications? }\end{array}$ \\
\hline \multicolumn{2}{|c|}{ (2) STUDY AND CONTEXT (SETTING, SAMPLE AND OUTCOME MEASUREMENT) } \\
\hline The Study & $\begin{array}{l}\text { - What type of study is this? } \\
\text { - What was the intervention? } \\
\text { - What was the comparison intervention? } \\
\text { Is there sufficient detail given of the nature of the intervention and } \\
\text { - What is the relationship of the study to the area of the topic } \\
\text { review? }\end{array}$ \\
\hline Context: (1) Setting & $\begin{array}{l}\text { - Within what geographical and care setting is the study carried out? } \\
\text { - What is the rationale for choosing this setting? } \\
\text { - Is the setting appropriate and/or sufficiently specific for } \\
\text { examination of the research question? } \\
\text { - Is sufficient detail given about the setting? } \\
\text { - Over what time period is the study conducted? }\end{array}$ \\
\hline Context II: Sample & $\begin{array}{l}\text { - What was the source population? } \\
\text { - What were the inclusion criteria? } \\
\text { - What were the exclusion criteria? } \\
\text { selected? (For example, theoretically informed, purposive, } \\
\text { convenience, chosen to explore contrasts) } \\
\text { - Is the sample (informants, settings and events) appropriate to the } \\
\text { aims of the study? } \\
\text { - If there was more than one group of subjects, how many groups } \\
\text { were there, and how many people were in each group? } \\
\text { - Is the achieved sample size sufficient for the study aims and to } \\
\text { warrant the conclusions drawn? } \\
\text { What are the key characteristics of the sample (events, persons, } \\
\text { times and settings)? }\end{array}$ \\
\hline $\begin{array}{l}\text { Context III: Outcome } \\
\text { Measurement }\end{array}$ & $\begin{array}{l}\text { - What outcome criteria were used in the study? } \\
\text { - Whose perspectives are addressed (professional, service, user, } \\
\text { carer)? } \\
\text { - Is there sufficient breadth (e.g. contrast of two or more } \\
\text { perspective) and depth (e.g. insight into a single perspective)? }\end{array}$ \\
\hline
\end{tabular}




\begin{tabular}{|l|l|}
\hline Review Area & \multicolumn{2}{|l|}{ Key Questions } \\
\hline (3) ETHICS & $\begin{array}{l}\text { Was Ethical Committee approval obtained? } \\
\text { Ethics }\end{array}$ \\
\hline Was informed consent obtained from participants of the study? \\
\hline (4) GROUP COMPARABILITY
\end{tabular}




\begin{tabular}{|c|c|}
\hline Review Area & Key Questions \\
\hline \multicolumn{2}{|c|}{ (6) POLICY AND PRACTICE IMPLICATIONS } \\
\hline Implications & $\begin{array}{l}\text { - To what setting are the study findings generalisable? (For example, } \\
\text { is the setting typical or representative of care settings and in what } \\
\text { respects? If the setting is atypical, will this present a stronger or } \\
\text { weaker test of the hypothesis?) } \\
\text { - To what population are the study's findings generalisable? } \\
\text { - Is the conclusion justified given the conduct of the study (For } \\
\text { example, sampling procedure; measures of outcome used and } \\
\text { results achieved?) } \\
\text { - What are the implications for policy? } \\
\text { - What are the implications for service practice? }\end{array}$ \\
\hline \multicolumn{2}{|c|}{ (7) OTHER COMMENTS } \\
\hline Other comments & $\begin{array}{l}\text { - What was the total number of references used in the study? } \\
\text { - Are there any other noteworthy features of the study? } \\
\text { - List other study references }\end{array}$ \\
\hline Reviewer & $\begin{array}{l}\text { - Name of reviewer } \\
\text { - Review date }\end{array}$ \\
\hline
\end{tabular}

${ }^{i}$ Long AF, Godfrey M, Randall T, Brettle AJ and Grant MJ (2002) Developing Evidence Based Social Care Policy and Practice. Part 3: Feasibility of Undertaking Systematic Reviews in Social Care. Leeds: Nuffield Institute for Health

-This tool was developed while the lead author was at the Health Care Practice R\&D Unit (HCPRDU) at the

University of Salford. It has since been slightly modified. 


\section{Appendice 5 Example of using CASP RCT checklist to appraise a selected RCT}

\begin{tabular}{|c|c|}
\hline \multicolumn{2}{|c|}{$\begin{array}{l}\text { Bibliographic Details: Emery, et al., ProCare Trial: a phase II randomized } \\
\text { controlled trial of shared care for follow-up of men with prostate cancer, BIU } \\
\text { International, Australia, } 2017 \text { [28] }\end{array}$} \\
\hline Screening questions & Score and reason \\
\hline $\begin{array}{l}\text { Did the trial address a clearly } \\
\text { focused issue? } \\
\text { Consider: An issue can be } \\
\text { 'focused' In terms of } \\
\text { - The population studied } \\
\text { - The intervention given } \\
\text { - The comparator given } \\
\text { - The outcomes considered }\end{array}$ & $\begin{array}{l}\text { Score: } 2 \\
\text { This study addressed a focused question. } \\
\text { First, there were clear inclusion and } \\
\text { exclusion criteria for the study population. } \\
\text { Second, the study procedures were also very } \\
\text { clear and detailed in both intervention group } \\
\text { and control group. Third, the trial reported all } \\
\text { outcomes clearly and the questionnaires } \\
\text { were suitable for the research purpose. }\end{array}$ \\
\hline $\begin{array}{l}\text { 2. Was the assignment of } \\
\text { patients to treatments } \\
\text { randomised? } \\
\text { Consider: } \\
\text { some methods may produce } \\
\text { broken allocation concealment } \\
\text { - Was the allocation } \\
\text { concealed from researchers? }\end{array}$ & $\begin{array}{l}\text { Score: } 2 \\
\text { The randomization was conducted by an } \\
\text { independent professional centre after both } \\
\text { patients and their GPs had signed informed } \\
\text { consent, so the allocation was concealed } \\
\text { from researchers. Although as mentioned in } \\
\text { the paper, there might be potential selection } \\
\text { bias because the relationship between } \\
\text { patients and practitioners could affect the } \\
\text { patients' decision about participation. } \\
\text { However, the author also provide a } \\
\text { reasonable explanation so that the rigor of } \\
\text { the study is not affected. }\end{array}$ \\
\hline $\begin{array}{l}3 . \text { Were } p \\
\text { and study } \\
\text { Consider: } \\
\text { - Heal } \\
\text { clinicians } \\
-\quad \text { Stud } \\
\text { especially }\end{array}$ & $\begin{array}{l}\text { Score: } 0 \\
\text { As for this research, it is impossible to blind } \\
\text { patients and practitioners because they are } \\
\text { aware of the whole process. But the study did } \\
\text { not mentioned about keeping outcome } \\
\text { assessors blinded, which is a shortage of this } \\
\text { research. }\end{array}$ \\
\hline $\begin{array}{l}\text { 4. Were the groups similar at the } \\
\text { start of the trial? } \\
\text { Consider: Look at } \\
\text { affect the outcome such as age, } \\
\text { sex, social class, these may be } \\
\text { called baseline characteristics }\end{array}$ & $\begin{array}{l}\text { Score: } 2 \\
\text { The important baseline factors such as age, } \\
\text { stage of cancer, and treatment type had been } \\
\text { considered and well balanced. The author } \\
\text { also stratified the allocation in the } \\
\text { randomization since patients came from } \\
\text { different treatment centres. }\end{array}$ \\
\hline $\begin{array}{l}\text { 5. Aside from the experimental } \\
\text { intervention, were the groups } \\
\text { treated equally? }\end{array}$ & $\begin{array}{l}\text { Score: } 1 \\
\text { This study had considered about balancing } \\
\text { two arms. All patients received five follow-up } \\
\text { visits, the difference between two group was } \\
\text { two specialist follow-up replaced by the GPs. } \\
\text { The only difference was the GPs visited the } \\
\text { patients at the beginning to re-engage with } \\
\text { them, which might affect the results. }\end{array}$ \\
\hline $\begin{array}{l}\text { accounted for at } \\
\text { Consider: } \\
\text { Was the tria } \\
\text { Were patien } \\
\text { he groups to wh }\end{array}$ & $\begin{array}{l}\text { Score: } 2 \\
\text { No evidence showed the trial stopped early. } \\
\text { All patients with results had been analysed } \\
\text { properly. }\end{array}$ \\
\hline
\end{tabular}




\begin{tabular}{|c|c|}
\hline randomised? & \\
\hline $\begin{array}{l}\text { 7. How large was the treatment } \\
\text { effect? } \\
\text { Consider: } \\
\text { - What outcomes were } \\
\text { measured? } \\
\text { - Is the primary outcome } \\
\text { clearly specified? } \\
\text { - What results were found for } \\
\text { each outcome? } \\
\text { - Is there evidence of } \\
\text { selective reporting of outcomes? }\end{array}$ & $\begin{array}{l}\text { Score: } 2 \\
\text { All outcome measurements were } \\
\text { patient-reported questionnaires. The } \\
\text { reliability and validity had been discussed in } \\
\text { the research protocol. The primary outcomes } \\
\text { included four questionnaire, a single specific } \\
\text { question about patients' preference of care } \\
\text { model, and a financial assessment. All } \\
\text { results had been reported clearly, and no } \\
\text { significant difference between two groups } \\
\text { expect the single specific question ( } P<0.001 \text { ). } \\
\text { Besides, no evidence indicated selective } \\
\text { reporting. }\end{array}$ \\
\hline $\begin{array}{l}\text { 8. How precise was the estimate } \\
\text { of the treatment effect? } \\
\text { Consider: } \\
\text { - What are the confidence } \\
\text { limits? } \\
\text { - Were they statistically } \\
\text { significant }\end{array}$ & $\begin{array}{l}\text { Score: } 2 \\
\text { The } 95 \% \text { confidence interval were provided } \\
\text { in the study, and the sample size could } \\
\text { provide } 80 \% \text { power to detect differences of } \\
0.6 \text { SD at two side. The significant } \\
\text { differences were defined as } P<0.05 \text {. }\end{array}$ \\
\hline $\begin{array}{l}\text { 9. Can the results be applied in } \\
\text { your context? (or to the local } \\
\text { population?) } \\
\text { Consider: } \\
\text { - Do you have reason to } \\
\text { believe that your population of } \\
\text { interest is different to that in the } \\
\text { trial } \\
\text { - If so, in what way? }\end{array}$ & $\begin{array}{l}\text { Score: } 1 \\
\text { Although the design of this research was } \\
\text { rigorous and clear, the system is different } \\
\text { from China. However, some developed area } \\
\text { in China begin to pay attention to primary } \\
\text { care, and this shared care model could be a } \\
\text { good model in the future. }\end{array}$ \\
\hline $\begin{array}{l}\text { 10. Were all clinically important } \\
\text { outcomes considered? } \\
\text { Consider: } \\
\text { - Is there other information } \\
\text { you would like to have seen? } \\
\text { clearly described? }\end{array}$ & $\begin{array}{l}\text { Score: } 1 \\
\text { Most important information has been } \\
\text { reported, and the needs also clearly } \\
\text { described. The limit was the number of } \\
\text { patients changed in the outcome report table, } \\
\text { but the author did not explain the reason. } \\
\text { Besides, the article did not mentioned how to } \\
\text { deal with incomplete questionnaires. }\end{array}$ \\
\hline $\begin{array}{l}\text { 11. Are the benefits worth th } \\
\text { harms and costs? } \\
\text { Consider: } \\
\text { Even if this is not } \\
\text { addressed by the trial, } \\
\text { - what do you think? }\end{array}$ & $\begin{array}{l}\text { Score: } 2 \\
\text { Since the results in this research showed that } \\
\text { shared care could provide similar outcomes } \\
\text { to usual care with lower costs, the benefit } \\
\text { worth all the efforts. }\end{array}$ \\
\hline Total & 17 \\
\hline
\end{tabular}

“0” represents many limitations, "1" represents some limitation, "2" represents excellent. 


\section{Appendice 6 Example of using HCPRDU quantitative research checklists to appraise a selected quantitative study}

\begin{tabular}{|c|c|}
\hline \multicolumn{2}{|c|}{$\begin{array}{l}\text { Bibliographic Details: Lund, Shared Care in prostate cancer: a three-year } \\
\text { follow-up, SCANDINAVIAN JOURNAL OF UROLOGY, Denmark, } 2016 \text { [35] }\end{array}$} \\
\hline Review Area & Score and Reason \\
\hline $\begin{array}{l}\text { (1) STUDY } \\
\text { OVERVIEW }\end{array}$ & $\begin{array}{l}\text { Score: } 1 \\
\text { This is a multicentre research which lasted for three years. } \\
\text { The bibliographic details were provided, and the key finding } \\
\text { was clearly defined. However, the weaknesses are the } \\
\text { definition of "shared care" was not detailed and the objective } \\
\text { of this study was not clear. }\end{array}$ \\
\hline $\begin{array}{l}\text { (2) STUDY, } \\
\text { SETTING, } \\
\text { SAMPLE AND } \\
\text { ETHICS }\end{array}$ & $\begin{array}{l}\text { Score: } 1 \\
\text { The limitation is the research type was not mentioned in the } \\
\text { content, and there was no comparison intervention. Besides, } \\
\text { whether the sample size was sufficient has not been defined, } \\
\text { which could not warrant the conclusions drawn. } \\
\text { The study was based on the shared care model, and the } \\
\text { patient discharge summery proceeded as the standard of } \\
\text { follow-up recommendation, which was provided to the GPs. } \\
\text { The inclusion and exclusion criteria were described. The } \\
\text { patients were enrolled from three hospitals and they were } \\
\text { stratified according to hospital, age, and treatment, the } \\
\text { dropout was also distributed to three hospitals, which could } \\
\text { warrant the conclusion. Besides, all the outcomes were } \\
\text { illustrated clearly as well as how to deal with the missing } \\
\text { data. }\end{array}$ \\
\hline (3) ETHICS & $\begin{array}{l}\text { Score: } 1 \\
\text { The paper did not mention about the ethical approval, but all } \\
\text { patients had given their consent. }\end{array}$ \\
\hline $\begin{array}{l}\text { (4) DATA } \\
\text { COLLECTION, } \\
\text { ANALYSIS AND } \\
\text { POTENTIAL } \\
\text { RESEARCHER } \\
\text { BIAS }\end{array}$ & $\begin{array}{l}\text { Score: } 1 \\
\text { The author had considered about the confounding variables } \\
\text { when analysing the data. The outcome measures were } \\
\text { appropriate in the study. All data was collected and provided } \\
\text { the sufficient details about the meaning. Besides, the length } \\
\text { of follow-up was three years, which was sufficient to detect } \\
\text { the effects. Although the non-responders could lead to some } \\
\text { bias, the dropout was equally distributed in terms of hospital } \\
\text { and age, and there was no difference between } \\
\text { non-responders and participants. } \\
\text { The limit is that there was no comparison and the validity and } \\
\text { reliability of questionnaires were not clarified, which might } \\
\text { affect the credibility of the conclusion. }\end{array}$ \\
\hline $\begin{array}{l}\text { (5) POLICY } \\
\text { AND } \\
\text { PRACTICE } \\
\text { IMPLICATIONS }\end{array}$ & $\begin{array}{l}\text { Score: } 2 \\
\text { The study findings underlined shared care could increase the } \\
\text { patient and GP compliance in cancer follow up, which could } \\
\text { be widely utilised in practice. }\end{array}$ \\
\hline $\begin{array}{l}\text { (6) OTHER } \\
\text { COMMENTS }\end{array}$ & $\begin{array}{l}\text { Score: } 2 \\
\text { The references were listed in the paper. In generally, it } \\
\text { provided a feasible way of follow up for cancer patients based } \\
\text { on a multicentre and long term research. }\end{array}$ \\
\hline Total & Score: 8 \\
\hline
\end{tabular}


Appendice 7 Example of using HCPRDU mixed methods research checklists to appraise a selected mixed methods' study

\begin{tabular}{|c|c|}
\hline \multirow[b]{2}{*}{ Question } & Score \\
\hline & $\begin{array}{l}\text { Bibliographic Details: Hanan, et al., Delivering care to } \\
\text { oncology patients in the community: an innovative } \\
\text { integrated approach, INNOVATIONS IN CARE, Ireland, } \\
2014 \text { [24] }\end{array}$ \\
\hline $\begin{array}{l}\text { (1) STUDY } \\
\text { OVERVIEW }\end{array}$ & $\begin{array}{l}\text { Score: } 1 \\
\text { The aim and key findings were described in the text. The } \\
\text { strengths of the study is that the intervention was } \\
\text { innovative and clearly defined, which provide a new way } \\
\text { to carry out shared care between hospital nurses and } \\
\text { community nurses. The weakness was that the } \\
\text { quantitative outcome measurements and results were } \\
\text { not clearly specified, and no data was reported. }\end{array}$ \\
\hline $\begin{array}{l}\text { (2) STUDY AND } \\
\text { CONTEXT } \\
\text { (SETTING, SAMPLE } \\
\text { AND OUTCOME } \\
\text { MEASUREMENT) }\end{array}$ & $\begin{array}{l}\text { Score: } 1 \\
\text { This study is mixed type study and the intervention was } \\
\text { quite clear and the design is very creative. There is } \\
\text { adequate detail in intervention group and comparison } \\
\text { group. The rationale for the study programme was } \\
\text { explained and the shared care was home-cased care } \\
\text { majorly conducted by community nurses. As for sample, } \\
\text { the author did not mentioned about how many } \\
\text { participants were involved in the quantitative procedure. } \\
\text { Besides, the outcome measurement was not mentioned } \\
\text { in the text. }\end{array}$ \\
\hline (3) ETHICS & $\begin{array}{l}\text { Score: } 1 \\
\text { The study obtained ethical approval and oral informed } \\
\text { consent was provided to the patients who joined the } \\
\text { qualitative interview. But whether the participants signed } \\
\text { informed consent was not mentioned. }\end{array}$ \\
\hline $\begin{array}{l}\text { (4) GROUP } \\
\text { COMPARABILITY }\end{array}$ & $\begin{array}{l}\text { Score: } 0 \\
\text { The author mentioned the data form three distinct time } \\
\text { points would be collected and compared to hospital } \\
\text { activity data, but no relevant data could be found in the } \\
\text { paper. }\end{array}$ \\
\hline $\begin{array}{l}\text { (5) QUALITATIVE } \\
\text { DATA COLLECTION } \\
\text { AND ANALYSIS }\end{array}$ & $\begin{array}{l}\text { Score: } 1 \\
\text { The data collection methods were provided, but the } \\
\text { process of fieldwork such as the interview guide and } \\
\text { length was not adequately described. The description of } \\
\text { data analysis process was mentioned but not sufficient. } \\
\text { The findings were quite clear. The interview and the } \\
\text { coding process were conducted by the researcher team, } \\
\text { so there might be some potential bias. }\end{array}$ \\
\hline $\begin{array}{l}\text { (6) POLICY AND } \\
\text { PRACTICE } \\
\text { IMPLICATIONS }\end{array}$ & $\begin{array}{l}\text { Score: } 1 \\
\text { The cancer survivors are increasing in the whole world. } \\
\text { The nurses play an important role in the management of } \\
\text { cancer patients. This research provide a good way to } \\
\text { combine oncology nurses and community nurses in the } \\
\text { integrated care. However, the programme might cost a } \\
\text { lot of money, which is the major obstacle of } \\
\text { implementation. }\end{array}$ \\
\hline $\begin{array}{l}\text { (7) OTHER } \\
\text { COMMENTS }\end{array}$ & $\begin{array}{l}\text { Score: } 1 \\
\text { Although the design of the study was quite good in this } \\
\text { mixed study, but more details about the data collection } \\
\text { and data analysis in both quantitative and qualitative part }\end{array}$ \\
\hline
\end{tabular}




\begin{tabular}{|l|l|}
\hline & should be covered. \\
\hline $\begin{array}{l}\text { Total score } \\
\text { (maximum 14) }\end{array}$ & 6 \\
\hline
\end{tabular}

"0" represents many limitations, "1" represents some limitation, "2" represents excellent 